\title{
TRANSLITERATIONS AND TRANSCRIPTIONS
}

O TRANSLITERATE, I REPRODUCE the consonants of the Semitic words by
using capital letters of the Roman alphabet. The following symbols are
used:

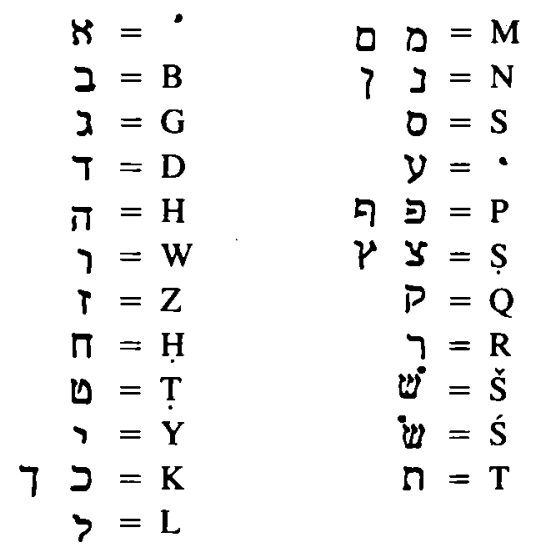

I also make use of a second system, transcription, which attempts to reproduce the vowel structure as well as the consonants. I use most of the same symbols as in the transliteration system, except that they appear as lower case letters in italics. There are, however, several different and additional symbols. In transcription I use $v$ for $\mathrm{W}$ and $s h$ for $\zeta$, and $v, k h$, and $f$ for spirants $\mathrm{B}, \mathrm{K}$, and $P$, respectively. Furthermore, I am not consistent in the indication of alef at the beginning of words.

Where a name has a fixed or standard rendering in English, I generally have used the English equivalent. Elsewhere, I have tried to reproduce the Hebrew; but I am not fully consistent in this matter. 


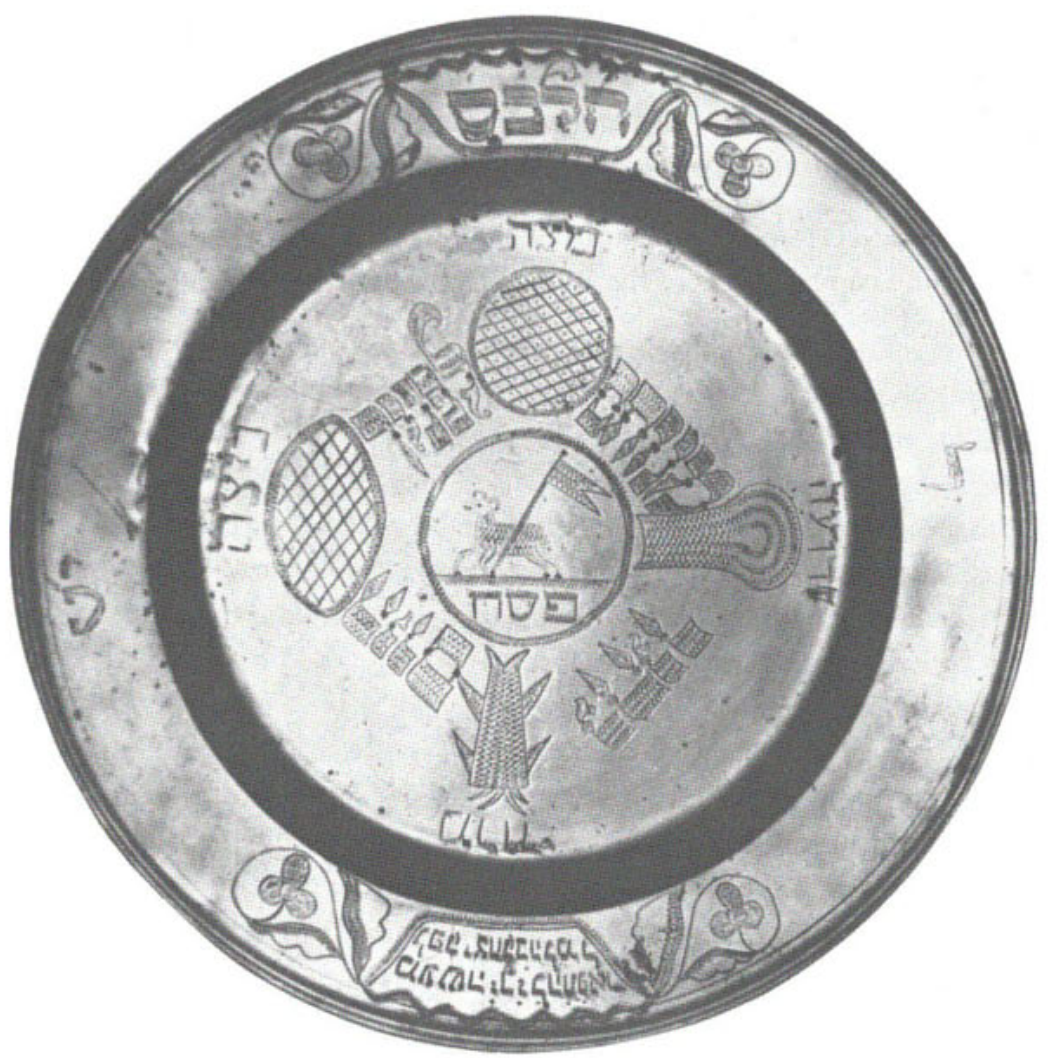

Illustration 1.

Passover plate with symbolic objects: the unleavened bread on top, bitter herbs on the bottom, and the passover lamb in the middle flanked by two symbolic substitutes, the egg and shankbone. The Jewish Museum/EPA F2255 Seder Plate, pewter, 1770 diameter 14'1/2". 


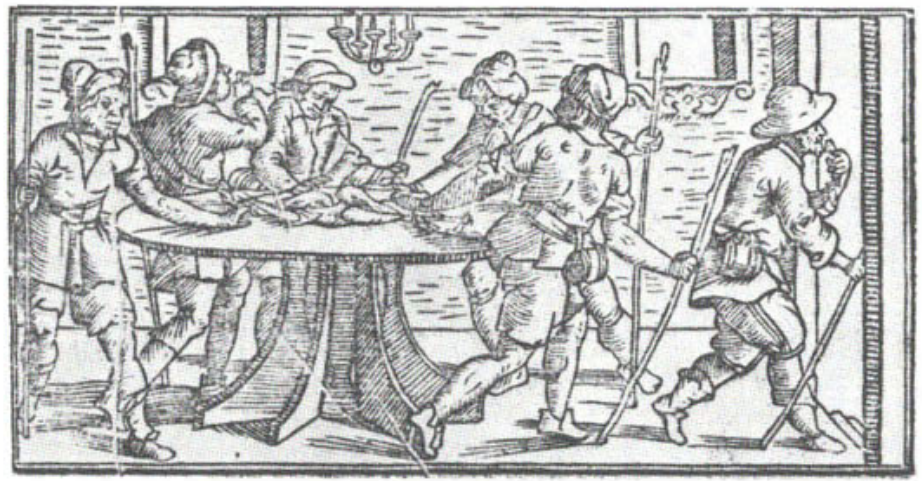

\section{Illustration 2.}

The biblical rite: eating the passover sacrifice. Participants are standing, with loins girded and staff in hand, eating the passover sacrifice in haste. Haggadah with German translation. Venice, 1663. Courtesy of the Library of the Jewish Theological Seminary of America.

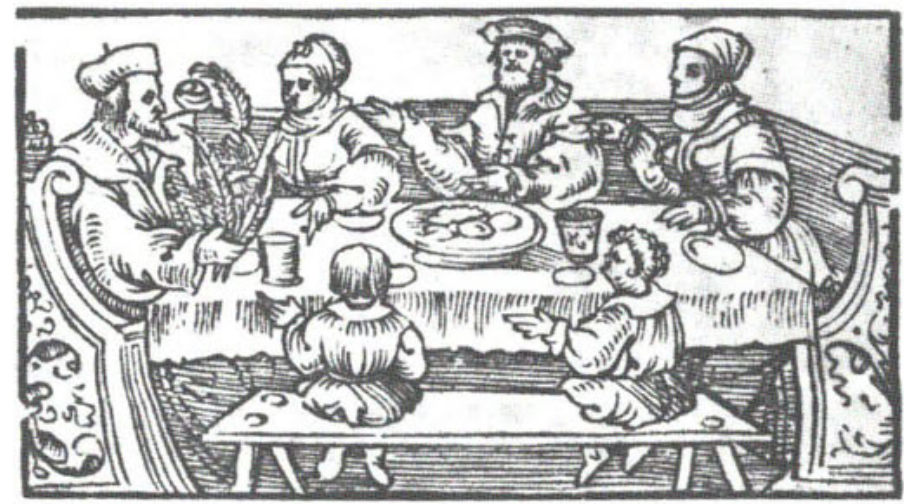

\section{Illustration 3.}

A rabbinic seder: without the sacrifice. The family participates in a meal with ritual objects at hand. Haggadah. Augsburg, Germany, 1534. Courtesy of the Library of the Jewish Theological Seminary of America. 
